\title{
O CASTELO ANIMADO E PIETÀ EM AQUARELA: UM ESTUDO DE EMOÇÕES, LUZ E SOMBRA
}

\author{
LETÍCIA PASSARELLI VERDE ${ }^{1}$
}

O longa-metragem O Castelo Animado (2004) dirigido pelo cineasta Hayao Miyazaki, que apresenta uma trama fantástica, belos enquadramentos e ricos detalhes.

A aquarela foi elaborada tomando como referência o próprio longa, e a escolha pessoal mediante a admiração pelo detalhamento que o filme apresenta, trabalhando a reflexão, observação, sensibilidade de cores e emoções. Possui dimensão de 14,8 x 21,0 cm, realiza da sobre papel de $240 \mathrm{~g} / \mathrm{m} 2$, e finalização em caneta nanquim e caneta branca.

Pietà é uma escultura renascentista de 1499 do artista Michelangelo. A obra retrata Jesus morto nos brações de sua mãe Maria, evocando emoções o mais próximo possível à realidade. Rigidamente calculada e seguindo composição triangular, dá sensação de impotência.

A obra foi selecionada para ser retratada a partir da técnica de aquarela, tendo como base uma ampliação da face de Maria para a realização de estudos das feições e emoções humanas, efeitos de luz e sombra e sobreposição de layers na cor azul a fim de criar profundidade a partir de uma superfície plana, o papel. Possui dimensões de 14,8 x 21,0 cm, realizada sobre papel de $300 \mathrm{~g} / \mathrm{m} 2$, e finalização em caneta nanquim e caneta branca.

1 Letícia Passarelli Verde é graduada em Arquitetura e Urbanismo pela Universidade Católica de Santos. leticia_passarelli@yahoo.com.br 


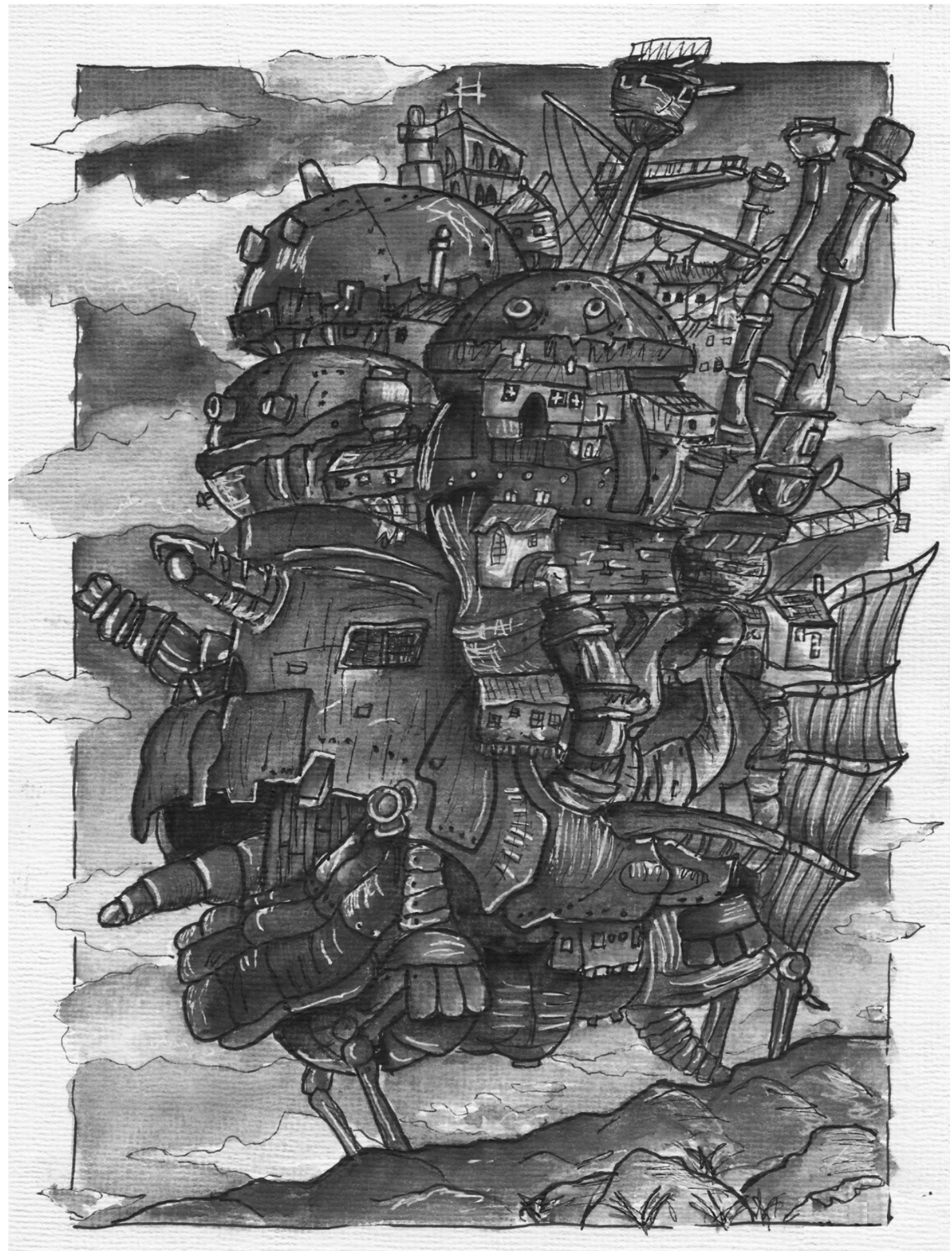




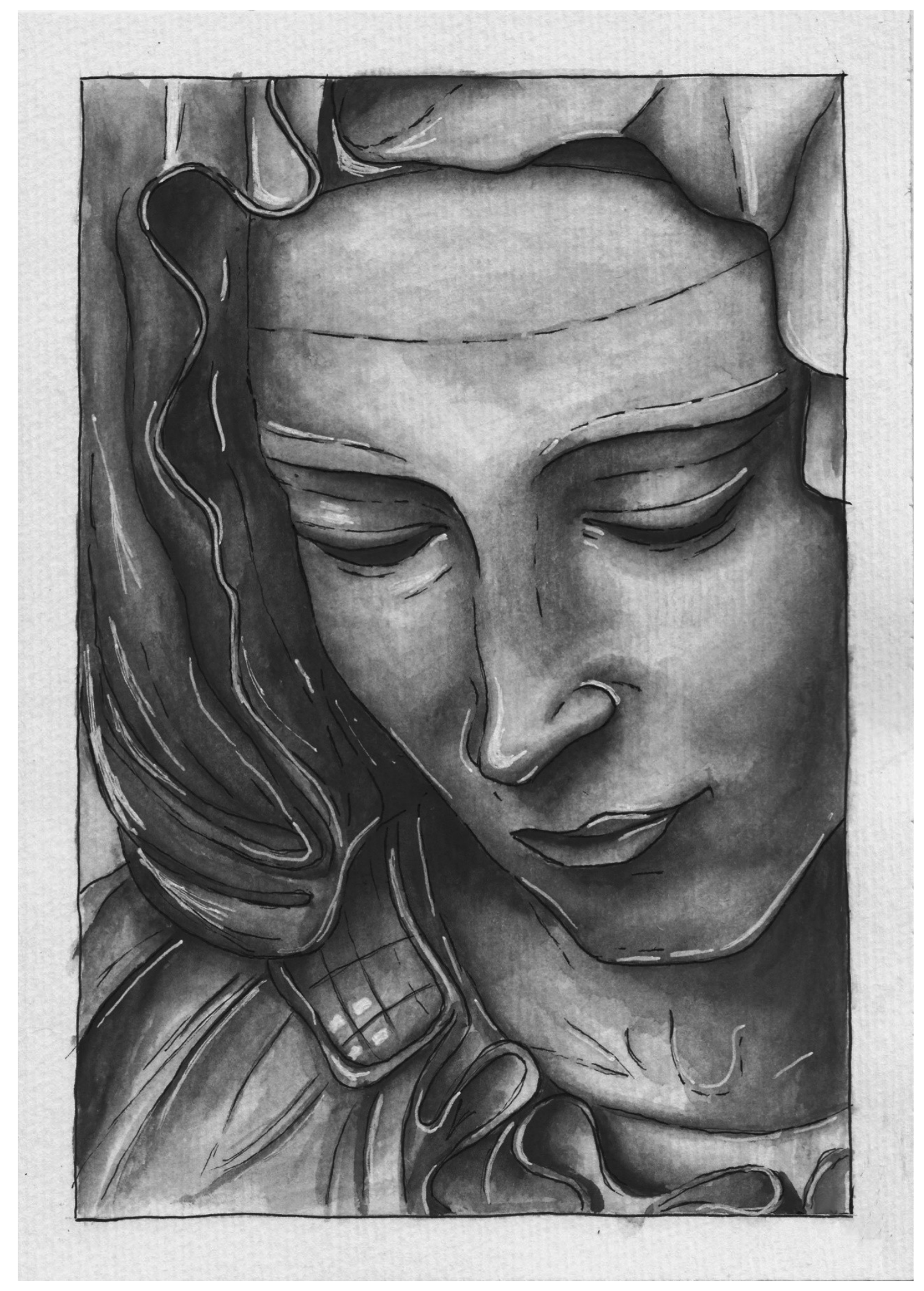




\section{REFERÊNCIAS}

Epoch Times. Nova iluminação realça beleza da obra Pietà, de Michelangelo. Disponível em: https://www.epochtimes.com.br/nova-iluminacao-realca-beleza-obra-pieta-michelangelo/. Acesso em: 19 jun 2019.

HAYAO Miyazaki: A Importância do Vazio. Entre Planos. 2016, 10:06 min, son., color. Disponível em: https://www.youtube.com/watch?v=Kyp3YV2t0gQ. Acesso em: 19 jun 2019. 